\title{
Risk factors for cardiovascular disease in HIV/AIDS patients treated with highly active antiretroviral therapy (HAART) in the central-southern region of the state of Paraná - Brazil
}

\author{
Fatores de risco para doença cardiovascular em pacientes com \\ HIV / AIDS tratados com terapia antirretroviral altamente ativa \\ (HAART) na região centro-sul do estado do Paraná-Brasil
}

Erildo Vicente Muller (https://orcid.org/0000-0003-4643-056X) ${ }^{1}$

Suely Godoy Agostinho Gimeno (https://orcid.org/0000-0002-3341-7676) ${ }^{2}$
${ }^{1}$ Universidade Estadual de Ponta Grossa. Av. General Carlos Cavalcanti 4.748, Uvaranas. 84030-900 Ponta Grossa PR Brasil. erildomuller@hotmail.com

${ }^{2}$ Departamento de

Medicina Preventiva,

Universidade Federal de São Paulo. São Paulo SP Brasil.

\begin{abstract}
The aim of this study was to describe metabolic changes in HIV/AIDS patients according to the treatment regimen. It was a retrospective cohort conducted from 2002 to 2014. Researchers surveyed clinical variables and treatment regimen of 538 individuals. They used measures of central tendency and marginal logistic regression to determine the influence of the treatment regimen on clinical variables over time; survival was estimated using Kaplan-Meier curves. $56.2 \%$ of patients were male, $82.2 \%$ white, $33.8 \%$ had 4 to 7 years of study, $49.2 \%$ were married, $98.5 \%$ had sexual transmission, and $89.0 \%$ were heterosexuals. During the study period, $24.4 \%$ had hypertension, $18.2 \%$ changed cholesterol, $39.7 \%$ low HDL, $51.3 \%$ high triglycerides and $33.3 \%$ hyperglycemia. Treatment regimens with nucleotide reverse transcriptase inhibitors associated with protease inhibitors, and the association of different classes of antiretrovirals have been associated with greater lipid changes. Higher metabolic changes were observed in patients with longer treatment time. It is concluded that preventive measures, as well as early treatment, can contribute to minimize the risks of developing cardiovascular diseases.
\end{abstract}

Key words Acquired immunodeficiency syndrome, Survival, Highly active antiretroviral therapy, Cardiovascular risk factor
Resumo O objetivo deste estudo foi descrever os fatores de risco cardiovascular em pacientes HIVI AIDS de acordo com o esquema terapêutico utilizado. Estudo de Coorte retrospectiva no período de 2002 a 2014. Foram levantadas variáveis clínicas e esquema de tratamento de 538 indivíduos. Utilizaram-se medidas de tendência central, e regressão marginal logística para verificar a influência do esquema de tratamento sobre variáveis clinicas ao longo do tempo. Dos pacientes, $56,2 \%$ eram homens, $82,2 \%$ brancos, $33,8 \%$ tinham entre 4 a 7 anos de estudo, 49,2\% eram casados, $98,5 \%$ tiveram transmissão sexual e $89,0 \%$ eram heterossexuais. A idade média no diagnóstico foi de 36,3 anos. Durante o periodo de estudo, 24,4\% hipertensão arterial, 18,2\% colesterol alterado, 39,7\% HDL baixo, 51,3\% triglicerídeos elevados e 33,3\% hiperglicemia. Os esquemas de tratamento com Inibidores da transcriptase reversa nucleotídeos associados a inibidores da protease, e a associação de diferentes classes de antirretrovirais estiveram associados a maiores alterações lipídicas e maiores alterações metabólicas com maior tempo de tratamento. Conclui-se que medidas preventivas, bem como tratamento precoce pode contribuir para minimizar os riscos de desenvolvimento de doenças cardiovasculares.

Palavras-chave Sindrome de imunodeficiência adquirida, Terapia antirretroviral potente, Fator de risco cardiovascular 


\section{Introduction}

Infection by carriers of human immunodeficiency virus and patients with acquired immunodeficiency syndrome (HIV/AIDS) has been a major public health problem in both developed countries and in developing countries. In 2015, there were 2,100,000 cases of new HIV infections worldwide, with a total of 36.7 million people living with HIV. In Brazil, in 2014, there were about 734,000 people living with HIV, with an estimated prevalence between 0.4 and $0.7 \%$ of the population, with estimated mortality by AIDS of 16,000 deaths $^{1}$.

The proportional distribution of AIDS cases in Brazil by region shows a concentration of cases in the Southeast and South regions, corresponding to $54.4 \%$ and $20.0 \%$ of cases identified from 1980 to June 2014; the Northeast, Midwest and North regions correspond to $14.3 \%, 5.8 \%$ and $5.4 \%$ of total cases. Over the past five years, Brazil has registered an average of 39,700 cases of AIDS. Regarding the regions, the North has an average of 3,500 cases per year; the Northeast, 7,900; Southeast, 17,000; South, 8,600; and the Midwest, 2,700².

In Brazil, since the beginning of the AIDS epidemic (1980) until December 2013 278,306 deaths had AIDS as the basic cause (ICD10: B20 to B24), mostly in the Southeast region (61.8\%), followed by South (17.3\%), Northeast (11.9\%), Midwest (5.0\%) and North region (4.0\%). In 2013 , the proportional distribution of 12,431 deaths was $44.0 \%$ in the Southeast, $21.2 \%$ in the South, $20.0 \%$ in the Northeast, 9.1 in the North and $5.8 \%$ in the Midwest ${ }^{2}$.

Since 1996 Brazil started to provide free treatment to people living with AIDS through the Unified Health System (SUS). As a result of this policy that provided an opportunity to universal access to treatment, there has been a sharp drop in mortality rates associated with AIDS. Brazil currently has the largest antiretroviral treatment (ART) coverage among low and middle income countries, in which nearly half of individuals living with HIV have received ART ${ }^{1}$.

Highly active antiretroviral therapy (HAART) in patients with acquired immunodeficiency syndrome is associated with metabolic disorders such as dyslipidemia, insulin resistance, diabetes and visceral obesity, risk factors related to early atherosclerosis ${ }^{3,4}$. Kamin and Grinspoon ${ }^{5}$ described metabolic disorders in a high proportion of patients treated with HAART regimens as well as increased risk of cardiovascular disease (coro- nary artery disease and cerebrovascular accident - CVA), especially in those who receive treatment with protease inhibitors (PIs).

Studies have reported a prevalence of dyslipidemia and other risk factors for cardiovascular disease in HIV/AIDS patients ranging from $20 \%$ to $80 \%$ in developed and developing countries ${ }^{6,7}$. Ximenes et al. ${ }^{8}$, in a study carried out in three regions of Brazil, showed that diabetes mellitus and hypercholesterolemia were more prevalent in the South region, with $8.5 \%$ and $11.7 \%$, respectively. The authors also showed a higher prevalence of triglycerides in the Northeast region (48\%).

With the use of combined antiretroviral therapy there has been increase in life expectancy of patients associated with the reduction of opportunistic infections; however, this population has been susceptible to chronic diseases and conditions related to risk factors common to the general population, mainly cardiovascular changes related to the adverse effects of antiretroviral drugs 9 .

The objective of this study was to determine the incidence of risk factors for cardiovascular diseases in HIV/AIDS patients living in the southern-central region of Parana state, according to the antiretroviral treatment regimen used.

\section{Method}

An epidemiological retrospective cohort study was conducted in HIV/AIDS patients at the Specialized Care Service of the municipality of Ponta Grossa - PR (SCS), which is a reference to the Southern-Central Region of Parana, serving patients from 12 municipalities, enrolled in the second Regional Area of Health. Data were collected based on medical records and health problems reporting forms.

The variables: date of birth, gender, race/ color; education, occupation, probable mode of transmission and sexual behavior were obtained through health problems reporting forms.

Authors analyzed 753 medical records of patients treated by SCS from January 2002 to December $2014(\mathrm{n}=538)$. Medical records of patients with previous alterations in metabolic parameters of interest were excluded. This procedure aimed to observe the influence of the drug regimen on the metabolic profile of the patients, thus totaling 538 medical records that were included in the study. Data were collected on weight $(\mathrm{kg})$, lipid profile (triglycerides, cholesterol, HDL cholesterol and LDL cholesterol, 
measured in $\mathrm{mg} / \mathrm{dl})$, blood glucose $(\mathrm{mg} / \mathrm{dl})$, and systemic blood pressure (SBP). The information was collected at a time interval of six months.

The reference values used to classify dyslipidemias were those recommended by the $\mathrm{V}$ Brazilian Guideline on Dyslipidemias and Prevention of Atherosclerosis ${ }^{10}$. For the classification of blood pressure levels, the VII Brazilian Guideline on Hypertension was used as reference ${ }^{11}$. For glycemia classification, the parameters established by the Brazilian Society of Diabetes were followed $^{12}$. CD4 count, viral load and treatment regimen were also checked.

The incidence estimates were made considering the number of person-years under observation.

In order to verify the factors influencing the change in blood pressure, cholesterol, HDL cholesterol, triglyceride and glycemia over time, the Marginal Logistic Regression was used. The marginal models, also known by GEE (Generalized Equations Estimating) method ${ }^{13}$, can be considered an extension of Generalized Linear Models ${ }^{14}$, which allow incorporating the expected correlation between the measurements performed in the same individual. Marginal Regressions, for their ease in interpretation and absence of distributional assumptions, have been preferred as an extension of Generalized Linear Models for dependent data ${ }^{15}$.

In order to select the variables (gender, race, schooling, marital status, mode of transmission, sexual behavior, regimen, age at diagnosis and weight) that could explain the occurrence of cardiovascular disease, researchers used the Stepwise method ${ }^{16}$. The Stepwise method is defined as a mixture of Backward and Forward methods, in which in the Forward method (variables entry criterion) a univariate analysis was performed by using the regression adjustment for each variable together with the variable time. Also, the interactions of all variables were tested with time, since as this is a longitudinal study, this type of interaction is expected to happen. For the Forward method it was adopted a $25 \%$ significance level. The selected variables and interactions were entered into a multivariate logistic marginal regression, and at this stage the Backward method was applied. The Backward method is the procedure to remove, at a time, the highest p-value variable, and this procedure is repeated until the only significant variables remain in the model. For the Backward method, it was adopted a 5\% significance level. It is noteworthy that when the presence of interactions with time was verified, authors decided to perform comparisons fixing times 0,995, 2,940 and 5,507, which correspond to the first, second and third quartile, respectively. The $\mathrm{R}$ software was used in the analyzes (version 3.2.2).

The research was conducted within the ethical standards and approved by the Research Ethics Committee of UNIFESP.

\section{Results}

538 HIV/AIDS patients were followed throughout the study in the central-southern region of the state of Parana. The follow-up time was 245.06 people/year, of which 119.58 women/ year and 125.48 men/year. The observed gender ratio was 1.28 males for every female. Of the individuals surveyed, $56.1 \%(\mathrm{n}=302)$ were male and $82.2 \%(n=439)$ were white, $16.1 \%(n=86)$ brown and $1.3 \%(\mathrm{n}=7)$ were black. $33.8 \%(\mathrm{n}=$ 152) of patients had 4 to 7 years of study, whereas only $7.8 \%(\mathrm{n}=35)$ had no education and $13.6 \%$ ( $\mathrm{n}=61)$ had 1 to 3 years of study. $49.2 \%$ ( $\mathrm{n}=$ 242) of patients were married, while $33.3 \%$ (n $=164$ ) were single. $98.5 \%$ of subjects had sexual mode of transmission and $89.0 \%$ were heterosexuals. Only $3.5 \%$ of patients had not used any treatment.

Table 1 shows the description of qualitative variables in terms of time. From this, one can note that: on average and over the study period, the percentage of patients with Regimen $\mathrm{C}$ was $40.6 \%$ and the percentage of untreated patients was $22.9 \%$. On average and over the study period, the percentage of abnormal blood pressure was $24.4 \%$; the percentage of altered cholesterol was $18.2 \%$; the percentage of altered HDL cholesterol was $39.7 \%$; the percentage of altered LDL cholesterol was $12.1 \%$; the percentage of altered triglycerides was $51.4 \%$ and the percentage of altered glycemia was $33.3 \%$. Regarding the size of the sample, it is also noteworthy that: the scheme showed 6,009 measurements relating to 537 patients. Therefore, on average, there were 11.20 measurements per individual. Blood pressure had 4,506 measurements concerning 520 patients. Therefore, on average, there were 8.67 measurements per individual. Cholesterol had 881 measurements related to 376 patients. Therefore, on average, there were 2.34 measurements per individual. HDL cholesterol had 705 measurements related to 351 patients. Therefore, on average, there were 2.01 measurements per individual. LDL cholesterol had 190 measurements 
relating to 118 patients, on average, there were 1.61 measurements per individual. Triglycerides had 887 measurements concerning 377 patients (on average, 2.35 measurements per individual). Blood glucose had 982 measures relating to 392 patients (2.51 measurements per individual, on average).

Table 2 shows the description of the quantitative variables (time between first and last visit, diagnosis time, age at the first visit, average time between the first and last visit and age at diagnosis). From this, it can be noted that: the average time between the first and last visit was 5.13 years, with a standard deviation of 3.67 years. The mean time between diagnosis and the last visit was 5.52 years, with a standard deviation

Table 1. Distribution of qualitative variables of HIV/ AIDS patients on antiretroviral treatment (over time) in the central-southern region of the state of Parana, 2002-2014.

\begin{tabular}{|c|c|c|c|}
\hline \multicolumn{2}{|c|}{ Variables } & \multirow{2}{*}{$\begin{array}{l}\mathbf{N} \\
59\end{array}$} & \multirow{2}{*}{$\begin{array}{c}\% \\
1.0 \%\end{array}$} \\
\hline Regimen & A & & \\
\hline$\left(n^{\star}=6009\right)$ & B & 2051 & $34.1 \%$ \\
\hline & $\mathrm{C}$ & 2438 & $40.6 \%$ \\
\hline & $\mathrm{D}$ & 85 & $1.4 \%$ \\
\hline & No treatment & 1376 & $22.9 \%$ \\
\hline \multirow{2}{*}{$\begin{array}{l}\text { Blood pressure } \\
\left(\mathrm{n}^{\star}=4506\right)\end{array}$} & Normal & 3406 & $75.6 \%$ \\
\hline & Changed & 1100 & $24.4 \%$ \\
\hline \multirow{2}{*}{$\begin{array}{l}\text { Cholesterol } \\
\left(\mathrm{n}^{\star}=881\right)\end{array}$} & Normal & 721 & $81.8 \%$ \\
\hline & Changed & 160 & $18.2 \%$ \\
\hline \multirow{2}{*}{$\begin{array}{l}\text { HDL Cholesterol } \\
\left(\mathrm{n}^{*}=705\right)\end{array}$} & Normal & 425 & $60.3 \%$ \\
\hline & Changed & 280 & $39.7 \%$ \\
\hline \multirow{2}{*}{$\begin{array}{l}\text { LDL Cholesterol } \\
\left(\mathrm{n}^{\star}=190\right)\end{array}$} & Normal & 167 & $87.9 \%$ \\
\hline & Changed & 23 & $12.1 \%$ \\
\hline \multirow{2}{*}{$\begin{array}{l}\text { Triglycerides } \\
\left(\mathrm{n}^{*}=887\right)\end{array}$} & Normal & 431 & $48.6 \%$ \\
\hline & Changed & 456 & $51.4 \%$ \\
\hline \multirow{2}{*}{$\begin{array}{l}\text { Glycemia } \\
\left(n^{\star}=982\right)\end{array}$} & Normal & 655 & $66.7 \%$ \\
\hline & Changed & 327 & $33.3 \%$ \\
\hline
\end{tabular}

of 4.31 years. The mean age at the first visit was 36.52 years, with a standard deviation of 10.88 years. The mean age at diagnosis was 36.33 years, with a standard deviation of 10.88 years.

Regarding the average incidence densities of risk factors for cardiovascular disease (CVD) per 1,000 people/year, it was found that this was 143.08 cases of abnormal blood pressure per 1,000 people/year, of which 97.90 were in females and 209.28 in males. The average incidence rate was 41.18 cases of altered cholesterol per 1,000 people/year, and in females the rate was 47.22 and in males, 35.10. The average incidence rate was 90.04 cases of altered HDL cholesterol per 1,000 people/year; in females, the average rate was 79.02 and in males, 102.68. The average incidence rate observed for altered LDL was 17.18 cases per 1,000 people/year; for females, the rate was 21.86 and for males, it was 11.59 . There was an average incidence rate of 126.84 cases of altered triglycerides per 1,000 people/year, with respective rates in women and men of 124.49 and 129.22. As for the blood glucose, the average incidence rate was 90.34 cases of changed glucose per 1,000 people/year; in females the rate was 87.86 , while for males it was 93.05 .

Table 3 shows the comparison of the regimen between the categories of variables. In all regimens there was a higher percentage of patients with normal cholesterol and HDL cholesterol, with the exception of regimen A, which had a higher percentage of patients with altered parameters. In untreated regimens, B and C there was a higher percentage of patients with normal LDL cholesterol. There was no information of LDL cholesterol for regimens A and D. In untreated regimens, $C$ and $D$, there was a higher percentage of patients with normal triglyceride levels, while in the regimens A and B there was a higher percentage of patients with altered triglycerides. In all regimens there was a higher percentage of subjects with normal glucose levels. The time had higher average in the regimen $\mathrm{D}$ and a lower average in the regimen $\mathrm{A}$. The age at diagnosis

Table 2. Description of Quantitative Variables at the Individual level (time between first and last visit, diagnosis time, age at the first visit, average time between the first and last visit and age at diagnosis in years) among patients treated with antiretroviral in southern-central region of Parana state.

\begin{tabular}{lcccccccc}
\hline \multicolumn{1}{c}{ Variables } & N & Average & S.D. & Min. & 1st Q & 2nd Q & 3rd Q & Max. \\
\hline Time between the first and the last visit & 537 & 5.13 & 3.67 & 0.00 & 1.70 & 5.00 & 7.97 & 12.80 \\
Diagnosis time until the last visit & 526 & 5.52 & 4.31 & 0.01 & 2.26 & 5.33 & 8.13 & 47.60 \\
Age at first visit & 531 & 36.52 & 10.88 & 16.90 & 28.70 & 35.01 & 43.66 & 74.80 \\
Age at diagnosis & 533 & 36.33 & 10.88 & 16.58 & 28.53 & 34.84 & 43.51 & 74.60 \\
\hline
\end{tabular}


Table 3. Comparison of treatment regimen and the categories of clinical variables.

\begin{tabular}{|c|c|c|c|c|c|c|c|c|c|c|c|}
\hline \multirow{2}{*}{\multicolumn{2}{|c|}{ Variables }} & \multicolumn{2}{|c|}{ Without } & \multicolumn{2}{|c|}{$A^{\star}$} & \multicolumn{2}{|c|}{$\mathbf{B}^{\star *}$} & \multicolumn{2}{|c|}{$C^{* * *}$} & \multicolumn{2}{|c|}{$D^{* * * *}$} \\
\hline & & $\mathbf{N}$ & $\%$ & $\mathbf{N}$ & $\%$ & $\mathbf{N}$ & $\%$ & $\mathbf{N}$ & $\%$ & $\mathbf{N}$ & $\%$ \\
\hline \multirow{2}{*}{$\begin{array}{l}\text { Blood } \\
\text { pressure }\end{array}$} & Normal & 468 & $73.8 \%$ & 44 & $83.0 \%$ & 1292 & $76.7 \%$ & 1573 & $76.1 \%$ & 29 & $43.3 \%$ \\
\hline & Changed & 166 & $26.2 \%$ & 9 & $17.0 \%$ & 392 & $23.3 \%$ & 495 & $23.9 \%$ & 38 & $56.7 \%$ \\
\hline \multirow[t]{2}{*}{ Cholesterol } & Normal & 75 & $89.3 \%$ & 3 & $33.3 \%$ & 304 & $81.5 \%$ & 331 & $81.7 \%$ & 8 & $80.0 \%$ \\
\hline & Changed & 9 & $10.7 \%$ & 6 & $66.7 \%$ & 69 & $18.5 \%$ & 74 & $18.3 \%$ & 2 & $20.0 \%$ \\
\hline HDL & Normal & 32 & $56.1 \%$ & 2 & $40.0 \%$ & 193 & $62.1 \%$ & 193 & $59.6 \%$ & 5 & $62.5 \%$ \\
\hline Cholesterol & Changed & 25 & $43.9 \%$ & 3 & $60.0 \%$ & 118 & $37.9 \%$ & 131 & $40.4 \%$ & 3 & $37.5 \%$ \\
\hline LDL & Normal & 16 & $80.0 \%$ & 0 & $0.0 \%$ & 80 & $87.9 \%$ & 71 & $89.9 \%$ & 0 & $0.0 \%$ \\
\hline Cholesterol & Changed & 4 & $20.0 \%$ & 0 & $0.0 \%$ & 11 & $12.1 \%$ & 8 & $10.1 \%$ & 0 & $0.0 \%$ \\
\hline \multirow[t]{2}{*}{ Triglycerides } & Normal & 49 & $55.1 \%$ & 4 & $44.4 \%$ & 142 & $38.1 \%$ & 230 & $56.7 \%$ & 6 & $60.0 \%$ \\
\hline & Changed & 40 & $44.9 \%$ & 5 & $55.6 \%$ & 231 & $61.9 \%$ & 176 & $43.4 \%$ & 4 & $40.0 \%$ \\
\hline \multirow[t]{2}{*}{ Glycemia } & Normal & 87 & $76.3 \%$ & 7 & $70.0 \%$ & 292 & $73.6 \%$ & 263 & $58.3 \%$ & 6 & $60.0 \%$ \\
\hline & Changed & 27 & $23.7 \%$ & 3 & $30.0 \%$ & 105 & $26.5 \%$ & 188 & $41.7 \%$ & 4 & $40.0 \%$ \\
\hline
\end{tabular}

${ }^{\star}$ other associations that did not fit in groups B, C and D. ${ }^{* \star}$ Nucleoside Reverse Transcriptase Inhibitors + Protease Inhibitors.

${ }^{* * \star}$ Nucleoside Reverse Transcriptase Inhibitors + Non-Nucleoside Reverse Transcriptase Inhibitors. ${ }^{* * \star}$ Nucleoside Reverse

Transcriptase Inhibitors + Non-Nucleoside Reverse Transcriptase Inhibitors + Protease Inhibitors.

had higher average in the regimen $\mathrm{D}$ and lower average in the regimen without treatment. The weight had higher average in the regimen $D$ and lower average in the regimen A. CD4 had a higher average in the regimen $\mathrm{D}$ and a lower average in the regimen A. CD8 showed higher average in the untreated regimen and a lower average in the regimen $\mathrm{C}$.

Table 4 presents the final multiple model of factors influencing the change in blood pressure, cholesterol, HDL cholesterol, triglyceride and glycemia.

In the univariate analysis performed for blood pressure, the variables age at diagnosis, weight, time and regimen were selected as predictive powers for the multiple model ( $\mathrm{p}$-value $<0.25$ ), in addition to the interaction between schooling $\mathrm{x}$ time, marital status $\mathrm{x}$ time, regimen $\mathrm{x}$ time and weight $x$ time. The final multiple model after applying the Backward method can be seen in Table 4 , in which it can be highlighted that the variables age at diagnosis, weight, time and regimen were significant, in addition to the interaction between time and regimen. Due to the interaction between time and regimen, the incidence of change in blood pressure was compared between regimens at different times of follow-up time. Thus, we can highlight that there was a significant influence $(\mathrm{p}<0.001)$ of age at diagnosis on blood pressure, and that with each year that increases in age, there is an increase of 1.05 times in the chance of having altered blood pressure. There was a significant influence $(\mathrm{p}<0.001)$ of weight on the arterial pressure, with each kilo- gram that increases in weight, there is a 1.06-fold increase in the chance of having altered blood pressure. At follow-up times 1 year and 3 years, there was no significant difference $(\mathrm{p}<0.05)$ between patients with and without treatment. On the other hand, at the time of 5.5 years, there was a significant difference $(\mathrm{p}=0.031)$ between regimen $\mathrm{A}$ and the patients without treatment, and the patients in regimen A had a chance of having blood pressure altered 2.83 times that of those without treatment. There was no significant influence of follow-up time on blood pressure in the untreated regimens, $A$ and $C(p>0.05)$. In regimen $B$, there was a significant influence $(\mathrm{p}=$ 0.011 ) of time on pressure, and with each year increased in time, the chance of having altered blood pressure increases by 1.29 times. On regimen $\mathrm{D}$, there was a marginally significant influence ( $p=0.052)$ of time, and with each year increased, the chance of having high blood pressure increased by 1.29 times. Age at diagnosis, weight, time and schedule were able to explain $20.4 \%$ of blood pressure variability.

In the univariate analysis performed for cholesterol, the variables gender, sexual behavior, regimen, age at diagnosis and weight were selected as predictor powers for the multiple model ( $p$-value $<0.25)$, as well as the interaction between race and time, schooling and time and regimen and time. The final multiple model after the application of the Backward method can be seen in Table 4. It shows that the variables gender, sexual behavior, age at diagnosis, weight, time and regimen were significant, besides the interaction between 
Table 4. Variables that influenced cardiovascular risk factors among patients undergoing antiretroviral treatment in the central-southern region of the state of Parana.

\begin{tabular}{|c|c|c|c|c|c|}
\hline \multicolumn{3}{|c|}{ Source } & \multirow{2}{*}{$\begin{array}{l}\text { O.R. } \\
1.05\end{array}$} & \multirow{2}{*}{$\begin{array}{c}\text { 95\% C.I. } \\
{[1.04 ; 1.06]}\end{array}$} & \multirow{2}{*}{$\begin{array}{l}\text { Valor-p } \\
<0.001\end{array}$} \\
\hline Blood pressure & Age at Diagnosis & & & & \\
\hline & Weight & & 1.06 & {$[1.05 ; 1.07]$} & $<0.001$ \\
\hline & Time $=1$ years & Regimen $=$ Without & 1.00 & - & - \\
\hline & & Regimen $=\mathrm{A}$ & 0.65 & {$[0.15 ; 2.92]$} & 0.577 \\
\hline & & Regimen $=\mathrm{B}$ & 0.77 & {$[0.55 ; 1.08]$} & 0.127 \\
\hline & & Regimen $=\mathrm{C}$ & 0.77 & {$[0.55 ; 1.08]$} & 0.127 \\
\hline & & Regimen $=\mathrm{D}$ & 0.80 & {$[0.30 ; 2.12]$} & 0.651 \\
\hline & Time $=3$ years & Regimen $=$ Without & 1.00 & - & - \\
\hline & & Regimen $=\mathrm{A}$ & 1.23 & {$[0.45 ; 3.32]$} & 0.688 \\
\hline & & Regimen $=\mathrm{B}$ & 0.98 & {$[0.71 ; 1.37]$} & 0.918 \\
\hline & & Regimen $=\mathrm{C}$ & 0.98 & {$[0.71 ; 1.37]$} & 0.918 \\
\hline & & Regimen $=\mathrm{D}$ & 1.27 & {$[0.53 ; 3.06]$} & 0.595 \\
\hline & Time $=5.5$ years & Regimen $=$ Without & 1.00 & - & - \\
\hline & & Regimen $=\mathrm{A}$ & 2.83 & {$[1.10 ; 7.25]$} & 0.031 \\
\hline & & Regimen $=\mathrm{B}$ & 1.35 & {$[0.84 ; 2.17]$} & 0.209 \\
\hline & & Regimen $=\mathrm{C}$ & 1.35 & {$[0.84 ; 2.17]$} & 0.209 \\
\hline & & Regimen $=\mathrm{D}$ & 2.34 & {$[0.87 ; 6.28]$} & 0.090 \\
\hline & Regimen $=$ Without & Time & 0.93 & {$[0.85 ; 1.02]$} & 0.146 \\
\hline & Regimen = A & Time & 1.29 & {$[0.90 ; 1.86]$} & 0.170 \\
\hline & Regimen $=\mathrm{B}$ & Time & 1.06 & {$[1.01 ; 1.11]$} & 0.011 \\
\hline & Regimen $=\mathrm{C}$ & Time & 0.99 & {$[0.95 ; 1.04]$} & 0.805 \\
\hline & Regimen $=\mathrm{D}$ & Time & 1.19 & {$[1.00 ; 1.41]$} & 0.052 \\
\hline \multirow[t]{23}{*}{ Cholesterol } & Gender $=$ Female & & 1.00 & - & - \\
\hline & Gender = Male & & 0.36 & {$[0.18 ; 0.72]$} & 0.004 \\
\hline & Sexual behavior $=\mathrm{H}$ & sexual & 1.00 & - & - \\
\hline & Sexual behavior $=\mathrm{Bi}$ & & 3.92 & {$[1.30 ; 11.80]$} & 0.015 \\
\hline & Sexual behavior $=\mathrm{H}$ & sexual & 1.97 & {$[0.63 ; 6.18]$} & 0.247 \\
\hline & Age at Diagnosis & & 1.06 & {$[1.03 ; 1.08]$} & $<0.001$ \\
\hline & Weight & & 1.03 & {$[1.01 ; 1.04]$} & 0.003 \\
\hline & Time $=1$ years & Regimen $=$ Without & 1.00 & - & - \\
\hline & & Regimen $=\mathrm{A}$ & 1.65 & {$[0.40 ; 6.87]$} & 0.492 \\
\hline & & Regimen $=\mathrm{B}$ & 0.95 & {$[0.28 ; 3.24]$} & 0.929 \\
\hline & & Regimen $=\mathrm{C}$ & 0.95 & {$[0.28 ; 3.24]$} & 0.929 \\
\hline & Time $=3$ years & Regimen $=$ Without & 1.00 & - & - \\
\hline & & Regimen $=\mathrm{A}$ & 12.43 & {$[1.44 ; 107.34]$} & 0.022 \\
\hline & & Regimen $=\mathrm{B}$ & 1.28 & {$[0.45 ; 3.63]$} & 0.639 \\
\hline & & Regimen $=\mathrm{C}$ & 1.28 & {$[0.45 ; 3.63]$} & 0.639 \\
\hline & Time $=5.5$ years & Regimen $=$ Without & 1.00 & - & - \\
\hline & & Regimen $=\mathrm{A}$ & 179.47 & $\begin{array}{r}{[2.71} \\
11901.27]\end{array}$ & 0.015 \\
\hline & & Regimen $=\mathrm{B}$ & 1.92 & {$[0.46 ; 7.94]$} & 0.368 \\
\hline & & Regimen $=\mathrm{C}$ & 1.92 & {$[0.46 ; 7.94]$} & 0.368 \\
\hline & Regimen $=$ Without & Time & 0.91 & {$[0.65 ; 1.28]$} & 0.592 \\
\hline & Regimen $=\mathrm{A}$ & Time & 2.58 & {$[1.12 ; 5.90]$} & 0.025 \\
\hline & Regimen $=\mathrm{B}$ & Time & 1.07 & {$[0.93 ; 1.22]$} & 0.351 \\
\hline & Regimen $=\mathrm{C}$ & Time & 1.00 & {$[0.85 ; 1.18]$} & 0.959 \\
\hline
\end{tabular}


Table 4. Variables that influenced cardiovascular risk factors among patients undergoing antiretroviral treatment in the central-southern region of the state of Parana.

\begin{tabular}{|c|c|c|c|c|c|}
\hline \multicolumn{3}{|c|}{ Source } & O.R. & 95\% C.I. & Valor-p \\
\hline \multirow[t]{4}{*}{ HDL } & \multicolumn{2}{|l|}{ Gender $=$ Female } & 1.00 & - & - \\
\hline & \multicolumn{2}{|l|}{ Gender $=$ Male } & 1.75 & {$[1.15 ; 2.65]$} & 0.008 \\
\hline & \multicolumn{2}{|l|}{ Weight } & 1.02 & {$[1.01 ; 1.03]$} & 0.005 \\
\hline & \multicolumn{2}{|l|}{ Time } & 0.93 & {$[0.88 ; 0.99]$} & 0.019 \\
\hline \multirow[t]{6}{*}{ Triglycerides } & \multicolumn{2}{|c|}{ Regimen $=$ Without treatment } & 1.00 & - & - \\
\hline & \multicolumn{2}{|c|}{ Regimen $=\mathrm{A}$} & 0.98 & {$[0.11 ; 9.01]$} & 0.988 \\
\hline & \multicolumn{2}{|l|}{ Regimen $=\mathrm{B}$} & 2.86 & {$[1.57 ; 5.20]$} & 0.001 \\
\hline & \multicolumn{2}{|l|}{ Regimen $=\mathrm{C}$} & 1.18 & {$[0.66 ; 2.11]$} & 0.578 \\
\hline & \multicolumn{2}{|l|}{ Age at Diagnosis } & 1.03 & {$[1.02 ; 1.05]$} & $<0.001$ \\
\hline & \multicolumn{2}{|l|}{ Weight } & 1.04 & {$[1.02 ; 1.05]$} & $<0.001$ \\
\hline \multirow[t]{21}{*}{ Glycemia } & \multicolumn{2}{|c|}{ Sexual behavior $=$ Heterosexual } & 1.00 & - & - \\
\hline & \multicolumn{2}{|c|}{ Sexual behavior $=$ Bisexual } & 2.51 & {$[1.06 ; 5.98]$} & 0.037 \\
\hline & \multicolumn{2}{|c|}{ Sexual behavior $=$ Homosexual } & 0.86 & {$[0.38 ; 1.98]$} & 0.730 \\
\hline & \multicolumn{2}{|c|}{ Age at Diagnosis } & 1.06 & {$[1.04 ; 1.08]$} & $<0.001$ \\
\hline & \multicolumn{2}{|l|}{ Weight } & 1.03 & {$[1.01 ; 1.04]$} & $<0.001$ \\
\hline & \multirow[t]{4}{*}{ Time $=1$ year } & Regimen $=$ Without & 1.00 & - & - \\
\hline & & Regimen $=\mathrm{A}$ & 0.01 & {$[0.00 ; 0.04]$} & $<0.001$ \\
\hline & & Regimen $=\mathrm{B}$ & 1.19 & {$[0.56 ; 2.53]$} & 0.660 \\
\hline & & Regimen $=\mathrm{C}$ & 1.19 & {$[0.56 ; 2.53]$} & 0.660 \\
\hline & \multirow[t]{4}{*}{ Time $=3$ years } & Regimen $=$ Without & 1.00 & - & - \\
\hline & & Regimen $=\mathrm{A}$ & 0.16 & {$[0.05 ; 0.50]$} & 0.002 \\
\hline & & Regimen $=\mathrm{B}$ & 1.01 & {$[0.53 ; 1.90]$} & 0.987 \\
\hline & & Regimen $=\mathrm{C}$ & 1.01 & {$[0.53 ; 1.90]$} & 0.987 \\
\hline & \multirow[t]{4}{*}{ Time $=5.5$ years } & Regimen $=$ Without & 1.00 & - & - \\
\hline & & Regimen $=\mathrm{A}$ & 9.58 & {$[3.15 ; 29.17]$} & $<0.001$ \\
\hline & & Regimen $=\mathrm{B}$ & 0.81 & {$[0.40 ; 1.64]$} & 0.557 \\
\hline & & Regimen $=\mathrm{C}$ & 0.81 & {$[0.40 ; 1.64]$} & 0.557 \\
\hline & Regimen $=$ Without & Time & 1.22 & {$[1.05 ; 1.41]$} & 0.008 \\
\hline & Regimen $=\mathrm{A}$ & Time & 6.05 & {$[4.00 ; 9.15]$} & $<0.001$ \\
\hline & Regimen $=\mathrm{B}$ & Time & 1.12 & {$[1.03 ; 1.21]$} & 0.008 \\
\hline & Regimen $=\mathrm{C}$ & Time & 1.09 & {$[1.02 ; 1.16]$} & 0.012 \\
\hline
\end{tabular}

time and regimen. Regimen D had to be deleted from the model due to the fact it did not show any patient with abnormal cholesterol, which makes it impossible to compare it with other regimens. Thus, it can be noted that there was a significant influence ( $\mathrm{p}=0.004$ ) of gender on cholesterol, and men had 0.36 times lower chance of having altered cholesterol than women. There was a significant influence of sexual behavior on cholesterol, in which bisexual patients had 3.92 times higher chances to have altered cholesterol than heterosexual patients $(\mathrm{p}=0.015)$. There was a significant influence $(\mathrm{p}<0.001)$ of age at diagnosis on cholesterol, in which each year increased in age increased 1.06 time the chance of having altered cholesterol. There was a significant influence ( $p$ $=0.003$ ) of weight on cholesterol, in which each kilogram increased in weight increased 1.03 time the chance of having altered cholesterol. With a year of follow-up there was no significant difference $(p>0.05)$ between patients with and without treatment. But with three years of follow-up $(p=0.022)$ and 5.5 years $(p=0.015)$, there was significant difference between regimen $A$ and patients without treatment, in which regimen $\mathrm{A}$ patients had 12.43 times higher chance of having altered cholesterol and it was 179.47 times higher among those untreated, respectively. 
In the univariate analysis performed for HDL cholesterol, the variables gender, sexual behavior and weight were selected as potential predictive factors for the multiple model ( $\mathrm{p}$-value $<0.25$ ), in addition to the interaction between sexual behavior $\mathrm{x}$ time, schema $\mathrm{x}$ time, age at diagnosis $\mathrm{x}$ time and weight $\mathrm{x}$ time. The final multiple model after the application of the Backward method can be seen in Table 4 . The variables gender, weight and time were significant. There was a significant influence $(p=0.008)$ of gender on HDL cholesterol, in which men had 1.75 times higher chance of having altered HDL cholesterol than women. There was a significant influence $(p=0.005)$ of weight on HDL cholesterol, in which each kilogram increased in weight increased 1.02 times the chance of having altered HDL cholesterol. There was a significant influence $(\mathrm{p}=0.019)$ of time on HDL cholesterol, in which each year increased in time decreased 0.93 times the chance of having altered HDL cholesterol. Gender, weight and time were able to explain $7.5 \%$ of variability in HDL cholesterol.

In the univariate analysis performed for triglycerides, the variables gender, regimen, age at diagnosis and weight were selected as potential predictive factors for the multiple model ( $\mathrm{p}$-value $<0.25$ ), while no interaction was selected. The final multiple model after the application of the Backward method can be seen in Table 4. The variables gender, age at diagnosis, weight and regimen were significant. Regimen D had to be deleted from the model due to the fact it did not show any patient with abnormal cholesterol, which makes it impossible to compare it with other regimens. Thus, it can be noted that there was a significant influence of regimen on triglycerides, in which regimen B patients had 2.86 times higher chance to have changed triglyceride than the untreated $(\mathrm{p}<0.001)$. There was a significant influence $(p<0.001)$ of age at diagnosis on triglycerides, in which every year increased in age increase 1.03 times the chance of having altered triglycerides. Regimen, age at diagnosis and weight were able to explain $13.9 \%$ of variability in triglycerides. (Table 4).

In the univariate analysis performed for HDL, the variables gender, mode of transmission, sexual behavior, regimen, age at diagnosis and weight were selected as potential predictive factors for the multiple model ( $\mathrm{p}$-value $<0.25$ ), as well as interaction between gender and time, marital status and time, mode of transmission and time and regimen and time. The final multiple model after the application of the Backward method can be seen in Table 4. The variables sexual behavior, age at diagnosis, weight, time and regimen were significant, besides the interaction between time and regimen. Thus, it can be noted that there was a significant influence of sexual behavior on blood glucose levels, in which bisexual patients had 2.51 times higher chances to have altered glycemia than heterosexual patients $(\mathrm{p}=0.037)$. There was a significant influence $(\mathrm{p}<0.001)$ of age at diagnosis on blood glucose, in which every year increased in age increased 1.06 times the chance of having altered blood glucose. There was a significant influence $(p<0.001)$ of weight on glycemia, in which each kilogram increased in weight increased 1.03 times the chance of having altered blood glucose. There was significant difference in altered blood glucose between the regimen $A$ and regimen without treatment at 1 year $(\mathrm{p}<0.001), 3$ years $(\mathrm{p}=0.002)$ and 5.5 years of follow-up ( $\mathrm{p}<0.001)$, in which regimen A patients had 0.01 and 0.16 times lower chance of having altered blood glucose than the untreated with 1 to 3 years follow-up, respectively, and 9.58 times higher than the untreated with 5.5 years of follow-up. There was a significant influence of time on glycemia in all regimens $(p<0.05)$, in which each year increased in time increased 1.22; 6.05; 1.12 and 1.09 times the chance of having altered blood glucose for the regimens without treatment A, B and C, respectively. Sexual behavior, age at diagnosis, weight, time and regimen have been able to explain $20.9 \%$ of variability in blood glucose.

\section{Discussion}

It was found that $56.1 \%$ of the individuals surveyed were men. The gender ratio found was 1.28. $82.2 \%$ were white and $16.1 \%$ were brown; $62 \%$ of the individuals had primary and secondary education. It is also observed that the transmission route was sexual (98.5\%) between married people $(49.2 \%)$ and with heterosexual sexual behavior (89.0). On average and during the period studied, the percentage of altered blood pressure was $24.4 \%$. The percentages of total cholesterol, HDL cholesterol, LDL cholesterol and triglycerides were respectively: $18.2 \%$; $39.7 \% ; 12.1 \%$ and $51.4 \%$. Also, there was $33.3 \%$ of patients with altered glycemia. It was also found that $40.6 \%$ of patients underwent treatment regimen C. Treatment with nucleotide reverse transcriptase inhibitors associated with protease inhibitors (B), and the association of 
different classes of antiretrovirals were associated with higher lipid changes. Higher metabolic changes were observed in patients with longer treatment times.

It is observed that gender ratio has been decreasing in Brazil, with regional variations. In the north and northeast regions of Brazil, there has been a greater participation of men, whereas in the South region there has been a greater participation of women in AIDS cases, with a gender ratio of 1.6. It is observed in the present research greater participation of women in relation to that described for the region ${ }^{2}$. According to the Epidemiological Bulletin of the Ministry of Health $(2014)^{2}$, the highest concentration of AIDS cases in Brazil are among individuals aged between 25 and 39 years for both genders. Study by Ximenes et al. ${ }^{8}$ in three Brazilian cities reported that $56.8 \%$ of the population with AIDS was aged under 40 , with a proportion similar to that found in this study with an average of 36.3 years. Regarding education, in this study, $62 \%$ of the subjects had primary and secondary education, similar data to those released by the Brazilian Ministry of Health ${ }^{2}$. According to Vieira et al. ${ }^{17}$, in Brazil, $62.4 \%$ of people with HIV/AIDS have education up to high school, which is indicator of socioeconomic status between low and middle income. These findings show the pauperization trend of the epidemic with an increase of cases in individuals with low education ${ }^{18}$. Regarding the mode of transmission, marital status and sexual behavior, studies ${ }^{18,19}$ have suggested a change in the behavior of the disease, with heterosexualization of the HIV/AIDS epidemic and greater growth of heterosexual men infected, as well as the predominance of this mode of transmission of the disease, corroborating with the findings of this research ${ }^{16,17}$.

In recent years there has been increased survival time of patients treated with HAART, however, several antiretroviral drugs induce metabolic changes, particularly dyslipidemia characterized by hypertriglyceridemia, hypercholesterolemia, and decreased serum levels of HDL, which may or may not be associated with increased serum levels of LDL cholesterol ${ }^{20,21}$. The findings of the present study were higher than those found by Silva et al. ${ }^{22}$ in a study of the lipid profile of HIV/ AIDS patients in Sao Paulo. Our findings are in agreement with Currier e Havlir ${ }^{23}$ and Estrada et al. ${ }^{9}$, who showed that $60 \%$ and $48 \%$ of AIDS patients have altered hyperglycemia, dyslipidemia and blood pressure. It has been reported a higher incidence of hypertension in HIV-infect- ed patients compared to the general population ${ }^{24}$. Studies have suggested that antiretroviral therapy can induce increase in blood pressure ${ }^{25-27}$. There is no explanation in the literature whether the use of Nucleoside Reverse Transcriptase Inhibitors (regimen B and D) have greater influence on the increase in blood pressure, as suggested by the findings of this research. It was found, regarding total cholesterol, that treatment time has been associated with increased cholesterol levels, especially in regimen A. In the present study, a higher elevation of triglycerides with a longer treatment time was observed. These data are in agreement with those found in literature, showing that AIDS patients treated with HAART have more metabolic disorders, especially high triglycerides and cholesterol when compared with untreated patients ${ }^{22,28,29}$. These same researchers also found higher lipid levels in patients using a combination of HAART Nucleoside Analogue Reverse Transcriptase Inhibitors and Non-Nucleoside Analogue Reverse Transcriptase Inhibitors, whereas in this study there was greater lipid changes in patients using Nucleoside Analogue Reverse Transcriptase Inhibitors associated with protease inhibitors (regimen B). Regarding smaller lipid indexes presented by women, these may be due to the hormonal protection given mainly by estrogen hormones produced by them during the reproductive age.

In the present study, there was increase in blood glucose with an increase in treatment time in all therapeutic regimens, with an increasing trend over the time. Corroborating with these findings, the studies of Samaras ${ }^{30}$ and Karamchand et al. ${ }^{31}$ reported increased risk for diabetes in patients using HAART. But there is controversy in cohort studies regarding the increased risk for diabetes ${ }^{32}$.

This study had some limitations, among them, there was the lack of standardization and of some essential information in the medical records of patients; there was no information of some predictive variables of cardiovascular risk such as height, smoking and alcohol use. This limited the calculation of Body Mass Index (BMI) and the measurement of frequency of consumption of cigarettes and alcohol. It was also found that no examinations were required to monitor the lipid index of patients regularly, according to the Ministry of Health's recommendation. As strengths of the study, it can be highlighted that it is the first to present a sociodemographic and epidemiological profile of patients with HIV/ AIDS in HAART treatment in the south-central 
region of the state of Paraná. The present study also showed the antiretroviral associations that increase lipid levels, factors that increase the risk for cardiovascular complications in HIV/AIDS patients. Another point worth mentioning was the finding that nucleotide reverse transcriptase inhibitors (regimens B and D) would have a greater influence on blood pressure increase, a fact not described in the literature, which could only be verified by the follow-up of the patients over time.

The prospect is that this study can subsidize early interventions in the groups at greater risk, substitution of antiretroviral drugs when possible, use of lipid-lowering drugs, and measures of interdisciplinary interventions, aiming to minimize the factors associated with the development of complications.

\section{Collaborations}

In this research, SGA Gimeno and EV Muller were responsible for the design work, data collection, analysis, data interpretation and writing of the article and critical review. This study is part of an EV Muller researcher cohort study in post doctoral internship program of the Federal University of São Paulo.

\section{Conclusion}

Our data are the first to evaluate the association between HIV/AIDS and exposure to HAART in the central-southern region of the state of Parana. CVD in AIDS patients living with HIV/AIDS and under treatment with HAART has been an increasingly prevalent comorbidity, whose origins are not fully understood. However, CVD and specific HIV/AIDS risk factors should be considered for the implementation of early prevention and treatment strategies, personalized according to the clinical and sociodemographic profile of patients. We can conclude, therefore, that differentiated measures should be considered in the care of these patients. 


\section{References}

1. Join United Nations Programme on HIV/AIDS (UNAIDS). Global report: UNAIDS reporto on the global AIDS epidemic 2013. Geneva: World Health Organization (WHO); 2013.

2. Brasil. Ministério da Saúde (MS). Boletim Epidemiológico AIDS/DST. Brasília: MS; 2014.

3. Prosperi MC, Fabbiani M, Fanti I, Zaccarelli M, Colafigli M, Mondi A, D’Avino A, Borghetti A, Cauda R, Di Gianbenedetto S. Predictors of first-line antiretroviral therapy discontinuation due to drug-related adverse events in HIV-infected patients: a retrospective cohort study. BMC Infect Dis 2012; 12:296.

4. Chastain DB, Henderson H, Stover KR. Epidemiology and management of antiretroviral-associated cardiovascular disease. Open AIDS J 2015; 9:23-37.

5. Kamin DS, Grinspoon SK. Cardiovascular disease in HIV-positive patients. Aids 2005; 19(7):641-652.

6. Troll JG. Approach to dyslipidemia, lipodystrophy, and cardiovascular risk in patients with HIV infection. Curr Atheroscler Rep 2011; 13(1):51-56.

7. Reinsch N, Neuhaus K, Esser S, Potthoff A, Hower M, Mostardt S, Neumann A, Brockmeyer NH, Gelbrich G, Erbel R, Neumann T. Are HIV patients undertreated? Cardiovascular Risk factors in HIV: results of the HIVHEART study. Eur J Prev Cardiol 2012; 19(2):267-274.

8. Ximenes RA, Lacerda HR, Miranda-Filho DB, Maria de Fatima P, Montarroyos UR, Turchi MD, Nery MW, Martelli CM, Alencastro PR, Ikeda ML, Wolff FH, Brandao AB, Barcellos NT, Fuchs SC. Comparison between potential risk factors for cardiovascular disease in people living with HIV/AIDS in areas of Brazil. J Infect Dev Ctries 2015; 9(09):988-996.

9. Estrada V, Bernardino JI, Masiá M, Iribarren JA, Ortega A, Lozano F, Miralles C, Olalla J, Santos J, Elías MJ, Domingo P, Cruz AF. Cardiovascular risk factors and lifetime risk estimation in HIV-infected patients under antiretroviral treatment in Spain. HIV Clin Trials 2015; 16(2):57-65.

10. Xavier HT, Izar M, Faria Neto J, Assad M, Rocha V, Sposito A, Fonseca FA, Santos JE, Santos RD, Bertolami MC, Faludi AA, Martinez TLR, Diament J, Guimarães A, Forti NA, Moriguchi E, Chagas ACP, Coelho OR, Ramires JAF. V Diretriz brasileira de dislipidemias e prevenção da aterosclerose. Arq Bras Cardiol 2013; 101(4):1-20.

11. Sociedade Brasileira de Cardiologia. VII Diretriz Brasileira de Hipertensão Arterial. Arq Bras Cardiol 2016; 107(3):1-83

12. Sociedade Brasileira de Diabetes (SBD). Diretrizes da Sociedade Brasileira de Diabetes (2015-2016). São Paulo: A.C. Farmacêutica; 2016.

13. Liang K-Y, Zeger SL. Longitudinal data analysis using generalized linear models. Biometrika 1986; 73(1):1322.

14. McCullagh P, Nelder JA. Generalized Linear Models. London: Chapman and Hall; 1989.

15. Fitzmaurice GM, Laird NM, Ware JH. Applied longitudinal analysis. New York: John Wiley \& Sons; 2012.
16. Efroymson MA. Multiple regression analysis. In: Ralston A, Wilf HS. Mathematical methods for digital computers. New York: John Wiley \& Sons; 1960. p. 191203.

17. Vieira ACS, Rocha MSG, Head JF, Casimiro IMAPC. A epidemia de HIV/Aids e a ação do Estado. Diferenças entre Brasil, África do Sul e Moçambique. Revista Katálysis 2014; 17(2):196-206.

18. Barbosa Júnior A, Szwarcwald CL, Pascom ARP, Souza Júnior PRB. Tendências da epidemia de AIDS entre subgrupos sob maior risco no Brasil, 1980-2004. Cad Saude Publica 2009; 25(4):727-737.

19. Souza Neto AI, Peixoto JM, Moura AS, Fátima Bonolo P. Dislipidemia e Risco Cardiovascular na Terapia Antirretroviral: o manejo dos fatores modificáveis. Rev Bras Cardiol 2013; 26(1):26-32.

20. Fisher SD, Miller TL, Lipshultz SE. Impact of HIV and highly active antiretroviral therapy on leukocyte adhesion molecules, arterial inflammation, dyslipidemia, and atherosclerosis. Atherosclerosis 2006; 185(1):1-11.

21. Cunha J, Maselli LMF, Stern ACB, Spada C, Bydlowski SP. Impact of antiretroviral therapy on lipid metabolism of human immunodeficiency virus-infected patients: Old and new drugs. World J Virol 2015; 4(2):5677.

22. Silva EFR, Bassichetto KC, Lewi DS. Lipid profile, cardiovascular risk factors and metabolic syndrome in a group of AIDS patients. Arq Bras Cardiol 2009; 93(2):113-118.

23. Currier JS, Havlir DV. Complications of HIV disease and antiretroviral therapy. Top HIV Med 2005; 13(1):16-23.

24. Iloeje U, Yuan Y, L'italien G, Mauskopf J, Holmberg S, Moorman A, Wood KC, Moore RD. Protease inhibitor exposure and increased risk of cardiovascular disease in HIV infected patients. HIV Med 2005; 6(1):37-44.

25. Kaplan RC, Kingsley LA, Sharrett AR, Li X, Lazar J, Tien PC, Mack WJ, Cohen MH, Jacobson L, Gange SJ. Ten-year predicted coronary heart disease risk in HIV-infected men and women. Clin Infect Dis 2007; 45(8):1074-1081.

26. Dimala CA, Atashili J, Mbuagbaw JC, Wilfred A, Monekosso GL. Prevalence of hypertension in HIV/ AIDS patients on highly active antiretroviral therapy (HAART) compared with HAART-naïve patients at the Limbe Regional Hospital, Cameroon. PloS one 2016; 11(2):e0148100.

27. Thiébaut R, El-Sadr WM, Friis-Moller N, Rickenbach M, Reiss P, Monforte AD, Morfeldt L, Fontas E, Kirk O, De Wit S, Calvo G, Law MG, Dabis F, Sabin CA, Lundgren JD; Data Collection of Adverse events of anti-HIV Drugs Study Group. Predictors of hypertension and changes of blood pressure in HIV-infected patients. Antivir Ther 2005; 10(7):811-823.

28. Mulligan K. Metabolic abnormalities in patients with HIV infection. J Int Assoc Physicians AIDS Care (Chic) 2003; 2(2):66-74. 
29. Hemkens LG, Bucher HC. HIV infection and cardiovascular disease. Eur Heart J 2014; 35(21):1373-1381.

30. Samaras K. Prevalence and pathogenesis of diabetes mellitus in HIV-1 infection treated with combined antiretroviral therapy. J Acquir Immune Defic Syndr 2009; 50(5):499-505.

31. Karamchand S, Leisegang R, Schomaker M, Maartens G, Walters L, Hislop M, Dave JA, Levitt NS, Cohen K. Risk factors for incident diabetes in a cohort taking first-line nonnucleoside reverse transcriptase inhibitor-based antiretroviral therapy. Medicine 2016; 95(9).

32. Nix LM, Tien PC. Metabolic syndrome, diabetes, and cardiovascular risk in HIV. Current HIV/AIDS Reports 2014; 11(3):271-278.

Artigo apresentado em 24/02/2017

Aprovado em 28/08/2017

Versão final apresentada em 30/08/2017 